\title{
Aprender sobre el otro, bailando. La Danza en la promoción de las relaciones interculturales
}

\author{
Daniela Paola Paizano Jiménez
}

\section{Resumen}

Hablar del vínculo entre danza e interculturalidad es complejo, pues es remover las historias, las identidades, las culturas y con ellas los sentimientos de los integrantes de un grupo multicultural, como lo es la agrupación folklórica Nicaragua mía.

A través del análisis de las relaciones interpersonales que viven los bailarines de este grupo de danza, ha sido posible descubrir la importancia que han tenido la convivencia familiar, el compañerismo y la amistad para el aprendizaje de competencias interculturales. En otras palabras, lo que no se ve, y que va más allá de la puesta en escena es haber aprendido sobre las tradiciones y costumbres del otro.

En el grupo Nicaragua Mía convergen identidades diversas y diferentes cosmovisiones. Sin embargo lo que ha permitido a este grupo multicultural de transformarse en un grupo intercultural ha sido el papel activo que cada uno de los bailarines y la misma profesora de danza han jugado como mediadores culturales.

El método etnográfico nos permitió comprender este proceso de aprendizaje que lleva a los integrantes del grupo no solamente a redescubrir sus culturas, sino a interpretarlas y a traducirlas para los demás. Abriéndose al mismo tiempo a la posibilidad de conocer las raíces del otro y a valorarlas.

Palabras clave: Danza, Interculturalidad, Relaciones interpersonales, Aprendizaje, Mediador cultural.

\section{Abstract}

In order to talk about the link between dance an interculturalilty, is necessary to remove the history, identities, cultures, and feelings from the dancers that conform one of the most multicultural folkloric ballet group as Nicaragua Mía is.

Through the analysis of interpersonal relations living dancers of this dance group it has been possible to discover the role played family life, companionship and friendship for learning intercultural skills. In other words, what is not seen, and that goes beyond the staging is to have learned about the traditions and customs of the other.

In the Nicaragua Mía group converge different identities and different worldviews. But what has allowed this multicultural group become a cultural group has been the active role that each of the dancers and the same dance teacher played as cultural mediators.

The ethnographic method allowed us to understand the learning process leading to the group not only to rediscover their culture, but to interpret and translate for others. While opening the possibility to know the roots of the other and evaluate them.

Keywords: Dance, Intercultural, Interpersonal Relations, Learning, Cultural mediator 


\section{Introducción}

La danza enmarca tradiciones, costumbres y sobre todo cultura; es la expresión de la cotidianeidad de un pueblo. Por ello se forman agrupaciones en las cuales se destaca, promueve y rescata la cultura a través de los bailes. Cada agrupación de danza es liderada por un instructor/a que tiene un estilo único de enseñanza, quien transmite la cultura de su localidad a sus estudiantes en cada pieza musical y así amplía los conocimientos de cada uno de los bailarines, quienes forman parte esencial y los que presentan en el escenario el trabajo preparado.

Los bailarines pueden ser de una comunidad misma o bien de distintas comunidades y barrios, lo que particulariza a cada uno y bien genera nuevas relaciones sociales, interpersonales y por otro lado interculturales. De modo que la presente investigación que inicia en el 2014, aborda las particularidades de los integrantes del Grupo de Danza Nicaragua Mía, quienes son de diversas localidades del país y con esto comprender la convivencia intercultural que se vive antes de cada presentación cultural. cultura como tal e influye en su desenvolvimiento dentro del grupo; en cambio a nivel cultural se aprende del otro y en ese mundo que se descubre dentro del mismo, se crean redes de intercambio en donde muchas veces conllevan a los sentimientos del bailarín, su lado humano en donde desde los imaginarios colectivos desaparecen, se redescubren asimismos como a los demás y se aprende a valorizar y respetar cada cultura y con esto permite la integración de la universidad con los sectores educativo, social-cultural de cada una de las zonas provenientes de los integrantes de la agrupación.

Las investigaciones registradas se han quedado efímeras al abordar estas temáticas, ya que únicamente se ha colocado como base el análisis de las aptitudes artísticas y el desempeño que muestran los sujetos, pero no desde el punto de vista del comportamiento de los sujetos que es resultado de convivir en un ambiente multicultural de relaciones sociales y motivacionales. Por ende es necesario ampliar en nuevas perspectivas y documentarlo, siempre con una antropología comprometida con el estudio de la cotidianeidad de las culturas abiertas a cambios y rupturas.

El grupo de danza Nicaragua Mía nace aproximadamente hace catorce años, caracterizándose desde sus inicios, por ser un grupo multicultural de danza de unos 60 integrantes, de los becados internos de la Universidad Nacional Autónoma de Nicaragua. Tras la necesidad de comprender la transformación de lo multicultural a lo intercultural dentro de una agrupación de danza, que bien se da a través de las relaciones interpersonales y siendo ellos partícipes del proceso, es que surge una interrogante $i \mathrm{De}$ qué manera sus raíces culturales juegan un papel importante

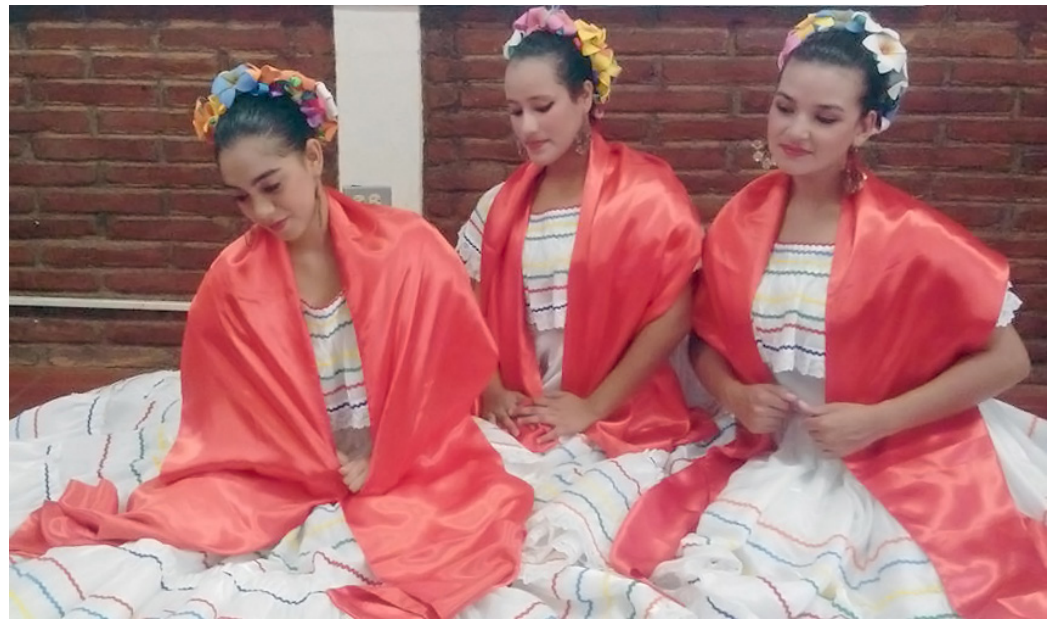

Interpretación a Margarita Calderón, UNAN-Managua. Mayo 2016 (Foto: Lesbia Grijalva) en la promoción de las relaciones interculturales y el aprendizaje grupal dentro de la danza como conducto integrador?

Es relevante destacar aspectos como lo social y lo cultural: en lo social es analizar los carácteres socioculturales que han adquirido a lo largo de su vida mediante factores como la procedencia, la que por ende encierra ciertas costumbres y tradiciones que forman parte de su
Por último es importante manifestar que tiene implicaciones prácticas, estas se revelan al determinar su participación, siendo ellos mismos, elementos claves para el logro de los objetivos que tienen como grupo; la comunicación con la instructora, que permite observar su integración en el aprendizaje colectivo, identificando debilidades y fortalezas en cuanto a conflictos internos o factores que conlleven a una buena organización; lo cual permite dar recomenda- 
ciones para lograr la sinergia en las relaciones sociales y desarrollo de las actividades artísticas.

\section{Antecedentes}

\section{La danza en varias facetas: "Nicaragua Mía" desde la diversidad cultural.}

A nivel local: En cuanto a documentación y estudios precisos de la agrupación de danza Nicaragua Mía, sólo se encuentra una investigación. Se trata de un trabajo investigativo denominado "El comportamiento social y la diversidad cultural en el Grupo de Danza Nicaragua Mía de los becados internos en la UNAN-Managua"; realizado en el 2013 por la Lic. Lesbia Grijalva Matamoros en ese entonces maestrante, que desde un enfoque antropológico trabaja la investigación, la cual explica la diversidad cultural a partir de los comportamientos y cómo inciden en el proceso artístico.

Se puede destacar que la diversidad cultural dentro del grupo de danza permite que sea multicultural y que a través de los comportamientos de los que habla Grijalva, se puede definir la transformación a intercultural debido a las interacciones entre los miembros de la agrupación, que bien se pueden observar en los ensayos. A nivel nacional, se encuentran ensayos dedicados a bailes con temas distintos, en muchos de estos se suele utilizar elementos que acompañen la escena y son muy significativos, es decir que ya son parte del baile o bien que representan el baile; un ejemplo de estos elementos son el uso de las máscaras.

En el 2011, fue publicado en Managua, un libro titulado "La Máscara y su presencia en Nicaragua", ela borado por Julio León Báez. En esta obra se explican las clases de danza, música y danza precolombina, la danza y la máscara y la influencia del teatro en la danza. Se refleja mucha tradición de la cultura nacional envuelta en las expresiones artísticas como la danza y el teatro, en lo que respecta a la danza explica cómo se vive la danza en Nicaragua y tipos de bailes tradicionales. Fue un referente que ayudó en la comprensión de tradiciones que enmarcan las regiones del país, de donde provienen los sujetos de estudio, en esta investigación de ahí sus comportamientos, además de cómo influye el teatro en la danza y adopción de personalidades al bailar.

A nivel internacional, se encontró una investigación realizada en varias comunidades pertenecientes a la sociedad $Y u$ 'pa ubicadas al noroeste de Venezuela. El artículo que tiene por título "La danza como modelo analítico de interpretación sociocultural", elaborado por Ángel Acuña Delgado, publicado en el 2002, presenta un análisis de la danza $y u^{\prime} p a$ vigente en las comunidades procedentes de la misma sociedad yu'pa perteneciente al caribe. Se trata de comunidades que con sus particularidades de acuerdo a varios factores que el autor presenta como la aculturación y transculturación por el cual pasa el grupo, son ejecutadas, dándoles continuidad y manteniendo de esta manera la danza yu'pa aunque en algunos casos con toques modernos.

En ese sentido el grupo de danza Nicaragua Mía tiene una estrecha relación, al trabajar con bailes tradicionales y modernos, tratando de rescatar la cultura o bien darle continuidad pero a la vez con un estilo único que es trabajado con la multiculturalidad que existe y que con las relaciones interpersonales abren un ambiente intercultural, apto para la aportación de ideas en cuanto a los bailes, siendo estos también, actores reales de la misma interpretación danzaria.

Los antecedentes encontrados tuvieron un aporte significativo para la investigación, tanto la información como metodologías utilizadas, las distintas formas de ver las realidades culturales y sociales que tienen que ver con la danza, los contrastes y relaciones que lograron un acercamiento tanto al grupo de danza como a la temática en particular.

\section{Elementos conceptuales claves de la investigación.}

El concepto de cultura ha sido ampliamente citado desde hace mucho tiempo en la antropología, sin embargo puntualizar su definicióna través de las palabras del antropólogo británico Edward Taylor no está demás: "Cultura es ese todo complejo que incluye el conocimiento, las creencias, el arte, la moral, el derecho, la costumbre y cualesquiera otros hábitos y capacidades adquiridos por el hombre como miembro de la sociedad." (Taylor, 1871).

En ese sentido la cultura se transmite de generación a generación mediante un proceso denominado enculturación, por el que un niño aprende su cultura y se le es transmitida, así mismo todos los integrantes de este grupo de danza originarios de diferentes regiones del país, vienen a la UNAN-MANAGUA, integran el grupo y comparten sus conocimientos 


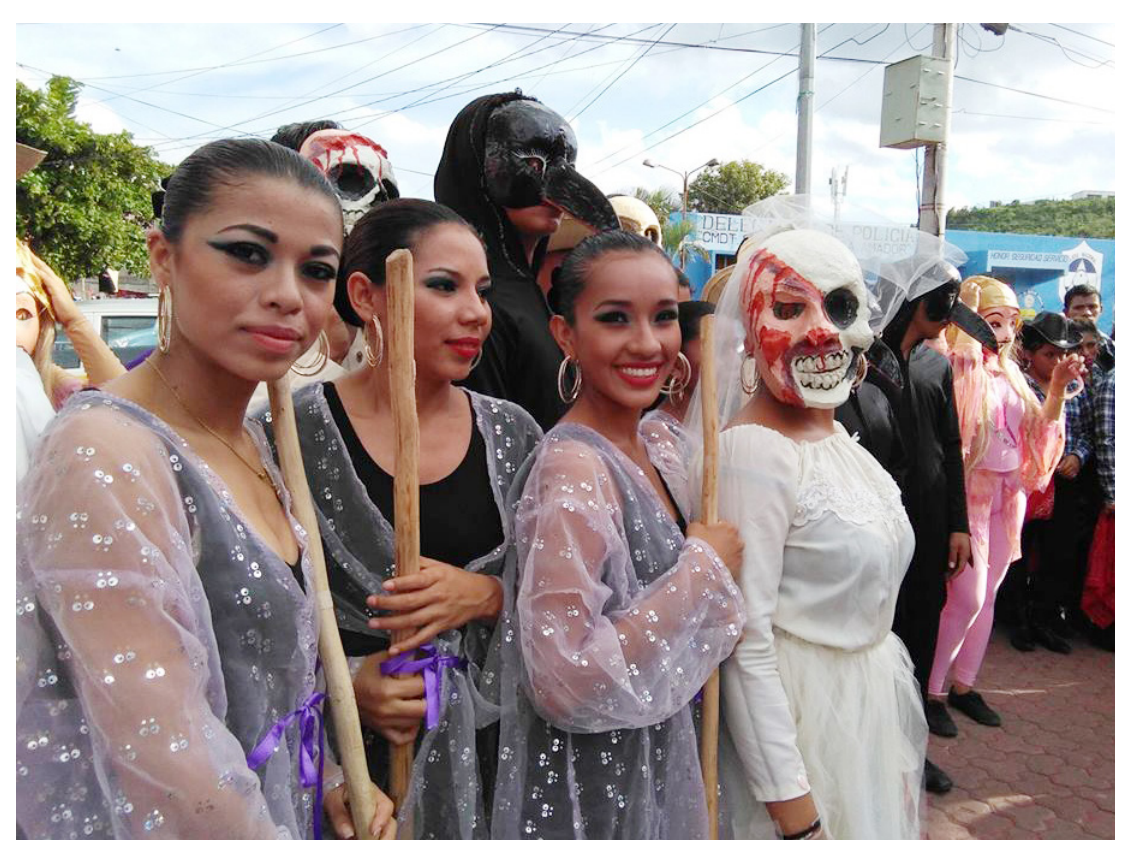

Pasa Calle con los Ahuizotes. Matagalpa. Junio 16-2016 (Foto: Lesbia Grijalva)
García Pastor, expresa que:

La mediación llamada hoy intercultural constituye un puente para favorecer el paso desde una realidad multicultural a otra intercultural. La tarea mediadora, vista desde esta perspectiva, empieza en el esfuerzo por construir la interculturalidad, a partir del conocimiento de las culturas, de las realidades culturales múltiples y del análisis de los diferentes procesos de contacto e interacción social (asimilación, exclusión, mestizaje, etc.). (Pastor, 2007)

Aproximándonos a uno de los puntos medulares de la investigación, los bailarines que integran este grupo de

arraigados a su cultura que incluye formas de bailar, hasta bailes propios de cada lugar.

La cultura la rigen los seres humanos como forma de responder las propias necesidades, y por lo general sin una base técnica. Es copartícipe, pues sus creadores y seguidores son los mismos individuos, que la crean y cultivan. Así en el grupo Nicaragua Mía, la interacción entre los miembros permite conocer de qué cultura vienen cada uno ellos y como conciben su cultura popular, comparten un sentido de pertenencia de cierto modo, pues todos son nicaragüenses, universitarios y artistas o bien quieren serlo.

Es debido comprender un poco sobre la cultura artística, que se puede definir como la serie de conocimientos adquiridos por una sociedad por medio del arte por lo que "llamamos arte a la actividad mediante la cual el ser humano expresa ideas, emociones o, en general, una visión del mundo, a través de recursos plásticos, lingüísticos, sonoros, o mixtos". (Joshert, 2008)

Al trabajar con un grupo de danza se puede apreciar el arte en cada uno de sus integrantes y en sus presentaciones se ve reflejada la cultura artística, no está exento en Nicaragua Mía, pues demuestran el arte en cada una de sus acciones, reflejan en sus bailes las realidades culturales de la historia del país y eso es arte. La doctora en Antropología Social y Cultural Begoña danza llegan a tener una convivencia intercultural y entender al menos la forma de ver la mediación de García, abre puertas para la comprensión de la realidad vivida dentro de la agrupación de danza en su nuevo contexto, la universidad.

\section{Por último, la universidad como contexto:}

La universidad constituye la unidad básica, primordial y fundamental en el sistema educativo, bajo la concepción de la figura responsable e insustituible dentro del proceso de enseñanza y aprendizaje, tanto en lo que se refiere a la planificación como a la ejecución de dichos procesos. (Naranjo \& Gonzalez, 2001)

La universidad del nuevo siglo debe enfrentar retos importantes ante los continuos cambios y crecientes rupturas paradigmáticas que suceden de manera continua en todas las áreas del conocimiento, generando un efecto en el conocimiento, la ciencia y la tecnología y los diversos sectores, esto incluyendo las áreas extracurriculares en donde figura la danza como parte ellas.

La institución universitaria, como sistema social, institucionaliza y refuerza normas y valores que influyen sobre el comportamiento de empleados, docentes y estudiantes. Todos éstos, por su parte, llevan consigo al lugar de trabajo, a las aulas y a los lugares en donde interactúan unos con otros, las ideas preconcebidas 
acerca de ellos mismos, de su auto-imagen, ¿quiénes son?, ¿qué merecen?, y ¿qué son capaces de realizar? es a través de las propiedades de adaptación de sus percepciones, que tratan de hacer coherentes sus opiniones, actitudes, conocimientos y valores con los de la sociedad y, particularmente, dentro de la institución (Castilllo, Lengua, 2011)

\section{Diseño metodológico}

Se utilizó el paradigma cualitativo, cuyo énfasis radica en analizar el entorno y cotidianeidad de los integrantes del grupo de danza Nicaragua Mía, permitiendo comprender los significados que los sujetos infieren a las acciones y conductas sociales, y que a partir de la subjetividad se pueda explicar su comportamiento.

Dentro del marco del paradigma cualitativo, he optado por el método etnográfico, que se caracteriza por ser un tipo de investigación descriptiva. De hecho, al aplicarlo, como investigadora, he concentrado mi atención en la descripción, comprensión e interpretación de los significados que los sujetos dan a sus propias acciones. En este caso específico, ha significado cuestionar el comportamiento de los integrantes del grupo de danza Nicaragua Mía. Es decir estudiar a este grupo de danza con sus actores, los bailarines, la instructora y el dirigente del Departamento de Becas de la Universidad, quien apoya y dirige también a los becados internos.

Haber optado por una investigación de corte etnográfico, me ha permitido experimentar una "forma de registrar narrativas orales" (Hammerrsley, 1983), y a la vez aplicar un método "mediante el cual el investigador produce datos que construyen la evidencia de un tipo particular de texto". (Guber, 2001).

La inserción al contexto primero como investigador y no como miembro fue un reto difícil: el papel del etnógrafo insider, que me tocó experimentar a raíz de pertenecer a este grupo de danza, significó en algunas ocasiones mantener distancia para ver desde otro ángulo lo que es familiar y de esta manera identificar lo que a simple vista no ha sido visible. En esa medida el análisis viene a ser debatible pero se retoma también la participación, lo observado y la visión antropológica y de esta manera se puede generar una discusión enmarcada en los valores en los que todas las partes se identifican.

Para entender un poco lo que es la entrevista desde el punto de vista antropológico en la investigación cualitativa, Ángel Aguirre Bastán nos plantea que esta "es una técnica dentro de la metodología cualitativa que se utiliza para obtener información verbal de unos o varios sujetos a partir de cuestionarios o guion." (Aguirre: 1995 p. 172).

La aplicación de la entrevista llenó vacíos y surgieron datos que no fueron premeditados: las entrevistas fueron de sondeo general y en otros casos a profundidad. En las primeras investigué aspectos generales que son importantes al constituir un pensamiento colectivo, es decir la percepción social sea uniforme o particular; y las otras fueron dirigidas a comprender las "perspectivas que tienen los informantes acerca de sus vidas, experiencias o situaciones". (Taylor y Bodgan en Atkinsón: 2005 p.178), que se viven dentro del grupo de danza.

Ricardo Barrantes, dice que la observación es necesaria en cualquier tipo de investigación, plantea que "es la técnica que permite ver a profundidad las cosas de las que se observan a simple vista". Algo que encontramos también en uno de los padres del método etnográfico, Bronislaw Malinoswky, quien agrega que la observación directa "integra todos los detalles observados y extraer la síntesis psicológica de los síntomas de diversas indoles en que puedan apoyarse." (Malinoswky, en Atkinsón: 1973 p. 178).

Para ello fue necesario mantener la distancia requerida para hacer extraño lo familiar, desaprender para aprender lo nuevo a estudiar y poder captar esas situaciones que no se observan si somos pares y en esa similitud son más profundas las relaciones y las emociones, por lo que esas mismas relaciones no son visibles si estoy de cerca, pero no quiero desacreditar la utilización y aprovechamiento de la observación participante, que por consiguiente se presenta.

El antropólogo Alfonso Maestre nos dice que en la investigación cualitativa en antropología social es necesaria la observación participante que es "la introducción del investigador en la comunidad objeto de la investigación y a base e integrarse como un miembro más de la sociedad para obtener los datos deseados." (Maestre: 1990 p. 55).

Mi integración a los ensayos del grupo de danza con esta nueva perspectiva, ya analizando a los sujetos y sus prácticas bajo los ejes de la investigación, fue muy productivo: yo seguía siendo parte de ellos, pero me esforzaba de mantener claros los objetivos planteados 
en la investigación-Así logré fortalecer cada punto importante de mi trabajo, a raíz de eso, la lógica de la entrevista se fue reacomodando, las preguntas tomaron forma y las respuestas de provecho.

La observación además sirvió para triangular la información obtenida en las entrevista, pues no solamente con escuchar, anotar o grabar se aprende del otro sino también como este acciona al hablar de lo que se le está preguntando, es decir sus gestos, con esto validar lo que está diciendo, además de notar su particularidad al expresarse con palabras.

El estudio abarcó a cierta parte de jóvenes que forman parte de un grupo de danza, los cuales son estudiantes universitarios y además becados internos, que también son personas de diferentes zonas del país con un solo propósito en común: aprender y formar parte de ese grupo de danza, además que es una actividad recreativa que pueden realizar sin afectar lo principal que en todo caso es su carrera profesional en esta universidad. Los actores en tal caso serían los integrantes del grupo de danza Nicaragua Mía, al igual que la maestra y personas del departamento de becas que conozcan acerca del grupo o que trabajen cercanamente con el grupo de danza que si bien se menciona pertenece al Departamento de Becas de la UNAN-Managua.

\section{Resultados}

Grupo de Danza Nicaragua Mía: origen y trayectoria artística.

Nicaragua Mía, es una agrupación de danza de la Universidad Nacional Autónoma de Nicaragua, Managua (UNAN-MANAGUA), la cual está conformada por 60 estudiantes de las diferentes carreras de la universidad. Estos jóvenes son originarios de distintas regiones del país, pero lo que tienen en común además del gusto por la danza, es que son becados internos. Los becados internos son una comunidad amplia dentro la UNAN-MANAGUA, de la cual se encarga el Departamento de Becas, atendiéndolos por facultad.

Surge hace quince años de la idea de dos jóvenes, Roger Horacio Centeno, estudiante de la carrera de Matemática Educativa y Silver Fuentes, estudiante de Informática Educativa, ambos becados internos.

Para explicar el inicio del grupo de danza se retoma el relato de Centeno, quien narra su experiencia:

En el primer semestre del 2001, cuando Silver me pide que le enseñe a bailar, empezamos ensayando en la casa número dos, donde practicábamos las coreografías que diseñaba y formaba para el MILAVF (Movimiento Infantil Luis Alfonso Velásquez Flores); luego Silver lleva a dos compañeras becadas internas y durante dos semanas practicábamos los cuatro; los demás compañeros se interesaron por aprender a bailar: salsa, merengue, folklore y ritmo urbano. (Centeno, 2014)

Cabe mencionar que el grupo de danza del MILAVF, mencionado en el testimonio, estaba ubicado en Tola-Rivas, donde el encargado era Centeno, el cual atendía los fines de semana que viajaba, pues ese es su lugar de origen.

Luego recurren a Doña Carmen Espinoza, encargada de la facultad de Educación e Idiomas en el Departamento de Becas en ese entonces, quien les brindó ayuda a Silver Fuentes y Roger Centeno.

"Doña Carmen Espinoza, nos prestó el comedor sin ningún problema y nos consiguió una grabadora, en ese momento ya éramos catorce becados internos y en tres meses el grupo se nos creció en número, pues llegamos a ser 28 integrantes." (Centeno, 2014)

El impulso de los mismos estudiantes motivó a otros a ser parte de este pequeño grupo, además del apoyo del Departamento de Becas desde una de las encargadas de facultad de los becados internos. Pero Centeno, quien era el cabecilla en ese entonces, pierde la beca interna en el segundo semestre de ese año y debe regresar a su comunidad, ya para ese entonces el grupo tenía nombre, Grupo de Danza Nicaragüense de Becados Internos y según Centeno, lo importante de ese grupo es que ya había algo que los representara como becados internos dentro de la universidad.

En ese momento de no saber qué hacer, se me ocurre proponerle al compañero del Grupo Camilo Zapata, Jonathan Caballero, que se hiciera cargo del grupo, porque era un grupo bastante grande y era una lástima que se disgregara y al haber perdido mi beca, tenía que regresar a $\mathrm{mi}$ pueblo (Tola-Rivas). (Centeno, 2014)

Lo que los jóvenes conocen acerca del inicio del grupo de danza es poco, sino solamente ya desde que lo retoma el profesor Jonathan Caballero hasta cuando pasa bajo la dirección de la profesora actual, Lesbia 
Grijalva.

Todos dicen conocer el cómo surge, las respuestas son diversas, pero cinco de ellos manejan la historia que relata Centeno, no con detalles, ni con exactitud, pero mantienen el orden que él asegura. Por esta razón se le da validez a lo que menciona, ya que la mayoría coincide, además de que la profesora Lesbia me remitió a Roger Centeno.

Al preguntarle a los entrevistados si antes de pertenecer al grupo conocían de su existencia, en su mayoría respondieron que no, a excepción de tres de ellos, el joven Junior Tobal (22 años de edad, estudiante de Licenciatura en Danza) porque vive cerca, además que estudiaba en Preparatoria; la joven Patricia (22 años de edad, estudiante de Derecho) porque un compañero de su grupo de danza en su comunidad, estudiaba en esta universidad y les platicaba del grupo porque el ya pertenecía también; la joven Sharon Aguilar (19 años de edad, estudiante de Economía agrícola) sabía de su existencia a través de su hermana que estudiaba en la universidad.

De acuerdo a las respuestas de los entrevistados, quienes son integrantes del grupo de danza, se asume que el grupo tiene de funcionar quince años aproximadamente, los miembros están en constante cambio, debido a que concluyen con sus carreras universitarias.

La mayoría de los entrevistados coinciden en tener 3 años de pertenecer al grupo, tres de ellas solo tiene dos años y tres que tienen 6 años de estar en el grupo, en este caso son jóvenes que se han cambiado de carreras o como el caso de Junior Tobal, que empezó en el grupo estando en preparatoria.

\section{Enseñanza-Aprendizaje}

$\mathrm{Al}$ igual que asemejan sus respuestas en cuanto al tiempo de integrar el grupo de danza, asimismo sucede al discutir el modo de enseñanza en comparación a los años anteriores y como es el trabajo en la actualidad; por un lado proponen los métodos de enseñanza que utilizaba con anterioridad la maestra, ya que se considera que la disciplina de los estudiantes no es muy buena y que la exigencia de la docente ha disminuido, en cambio otros difieren añadiendo que hoy en día ha mejorado ya que por ejemplo hay más captación de estudiantes por esos métodos de enseñanza.

A lo que Junior Tobal, integrante del grupo, dice:
Considero que hace cinco años la maestra era como más exigente en ese sentido nos exigía más en técnicas y teníamos otros maestros que venían de otros lados a impartir clases de teatro, nos daban técnica moderna, jazz clásico, entre otras cosas, ahora entra cualquiera, baila y es muy bonito pero, ya no tenemos la misma experiencia de antes considero yo, como bailarín viejo del grupo. (Tobal, 2014)

Leez García, siendo una de las integrantes con más tiempo de pertenecer al grupo, al igual que los de su generación, comparten ese pensamiento de que antes las estrategias de enseñanza-aprendizaje eran mejor que hoy en día:

Antes, la profesora era más estricta y los alumnos más disciplinados. Había aquel espíritu de competitividad en las alumnas y los alumnos. Siempre había una mejor bailarina en cuestión de que enamora con los movimientos que hacía, eran gente que ya habían bailado anteriormente entonces una siempre quería siempre ser igual o pasar a esa, no que solo dijeran, ¡la fulana esa es mejor, que lindo baila!, yo quiero que también hablen así de mí. Entonces eso existía antes y también que había responsabilidad en cuanto a que si decían a tal hora, a tal hora era y si no, no se podía entrar si vos llegaste cinco minutos después, pues quédate afuera, y entonces sí, creo que era más organizado y mucho mejor antes que ahora. (García, 2014)

Pero para otros, como Juan Ruiz es mejor ahora, pues se le abren las puertas a cualquiera que desee aprender e integrar el grupo, de alguna manera no hay excepción, para eso los talleres en donde enseñan a marcar el paso, el estilo del grupo, ayuda a afinar a cada estudiante, no hay discriminación de ninguna índole, pues ni el físico es impedimento, ya que también se hacen rutinas de ejercicios varios, para ayudar a que el cuerpo sea más flexible, a tener soltura y bien a mantener un cuerpo sano.

La organización del grupo está dada en dos encuentros debido a los dos grupos que se subdividen. Los encuentros son lunes, miércoles y jueves, el grupo de danza y martes y viernes los del taller. Los integrantes que ya van avanzados llegan a los días del taller, cuando pueden, y ayudan a la maestra a impartir la clase, ya sea en los ejercicios de entrada, como las coreografías que empiezan a enseñar para así ir integrando más muchachos al grupo. Las reuniones son de 7 a 9 de la 
noche, en el Salón de Danza pabellón 25, aula 2502.

Para la enseñanza-aprendizaje de los estudiantes en cada uno de los ensayos, se utilizan mecanismos que son presentados conforme a su concepto, de la siguiente manera:

\section{Pedagogía}

La maestra tiene Licenciatura en Danza y es una de las fundadoras del Ballet Folklórico Tepenáhuatl. Ésto aporta a la forma de relacionarse con los alumnos y como tal para impartir la clase, se tiene una mejor organización y control. El estudiante logra aprender aunque de inicio no sepa bailar, se le va enseñando por partes cada paso de baile, con una amplia explicación y son asemejados con situaciones del quehacer nicaragüense, que desde sus orígenes se ha dedicado a la tierra, primeramente como personas de la vida rural, como sus tradiciones y costumbres son reflejadas en las obras teatrales a través de los bailes que relatan sucesos históricos bien esas mismas tradiciones bien sean cambiantes o ya desvanecidas con el tiempo.

Un ejemplo claro de eso es con el baile del Mestizaje, es una pieza musical compuesta por fragmentos de otras piezas musicales como son la Danza Negra y el Mate Amargo; es música de marimba, en ella se representa la mezcla de españoles e indios y cómo nace el grupo étnico mestizo, como lo dice nuestra historia y como nos identificamos la mayoría de gente del país.

Luego de enseñar los pasos, los empieza a combinar y así formar una coreografía, después de marcar y tener los pasos, continua explicando la utilización de las manos, los gestos, el estilo de baile y la comunicación de la pareja tradicional a la que se imita.

\section{Técnicas}

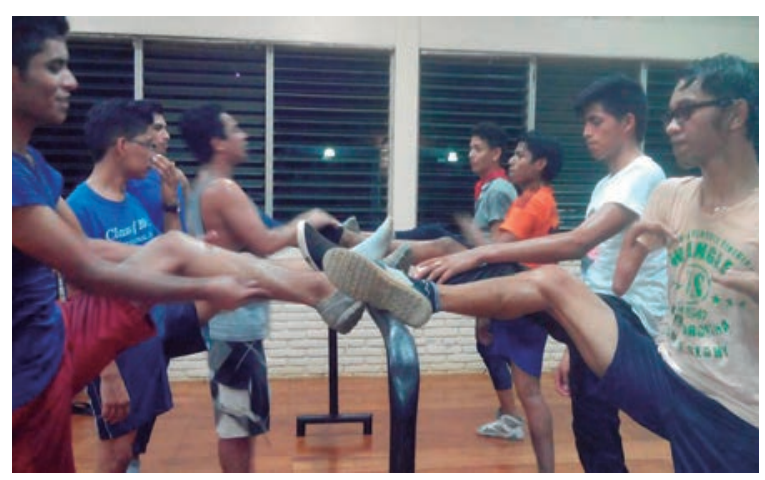

Estiramiento en barra, Salón de Danza, Pabellón 9, Aula 2502. Mayo 2016 (Foto: Lesbia Grijalva)
Son diferentes actividades como de entrada que se hacen ejercicios de relajamiento, de moldeo del cuerpo, para facilitar el desplazamiento, aumentar la habilidad y controlar la forma de respirar para evitar cansarse rápido, en ocasiones los alumnos no acatan bien las indicaciones a la hora de hacer los ejercicios y más de alguna vez se han lastimado, es por eso que la profesora pide concentración. Por otro lado, también enseña técnicas de ballet que son utilizadas para lograr la flexibilidad y soporte del peso propio de cada estudiante y fortalecer los músculos y huesos, trabajando las extremidades, el tórax, el cuello y el metatarso.

\section{Atención Psicológica}

A la maestra le gusta interactuar con sus alumnos, le importa el estado de ánimo que lleven al ensayo, y trata de apoyarlos cuando puede, no obliga a nada que no quieran, dejando a un lado que de momento que integran el grupo adquieren un compromiso. Trata de organizar el tiempo de prácticas a fin de que sus estudiantes no se vean afectados en las clases, con los exámenes, prácticas de la carrera, en fin. Le gusta que haya armonía en el grupo y trata de hacer amigos a todos, ya que las enemistades generan dificultad en el trabajo que se hace. Da acompañamiento en situaciones académicas a sus alumnos que le piden ayuda, y aconseja en el ámbito personal a los alumnos que le comparten sus problemas personales.

\section{Mediador: trabajo compartido}

La profesora cuando enseña un determinado baile, percibe a los estudiantes que aprenden con mayor facilidad los impulsa a que también enseñen a los otros y a veces les deja la clase a ellos y sólo les da indicaciones de lo que van a hacer o simplemente los muchachos de mayor tiempo en el grupo ya manejan la manera de entrenar y sin ninguna molestia comparten sus conocimiento haciendo más dinámicos los ensayos, pues muchas veces entre jóvenes se entienden mejor. Algunos de estos jóvenes son: Enrique Molina, Junior Tobal, Marlon Hurtado y Francisco Rocha.

Por otro lado también tiene que ver con la originalidad de los bailes como por ejemplo el baile de La Banana, un baile de la Costa Caribe, lo enseñó una joven integrante que es originaria de esta zona del país. Ella montó los pasos y decía que representaba cada uno de ellos, uno por ejemplo era el pedir la lluvia a los dioses, nadar, entre otras cosas, de las que nuestra gente hacía y hace en su vida cotidiana. El trabajo de la profesora 


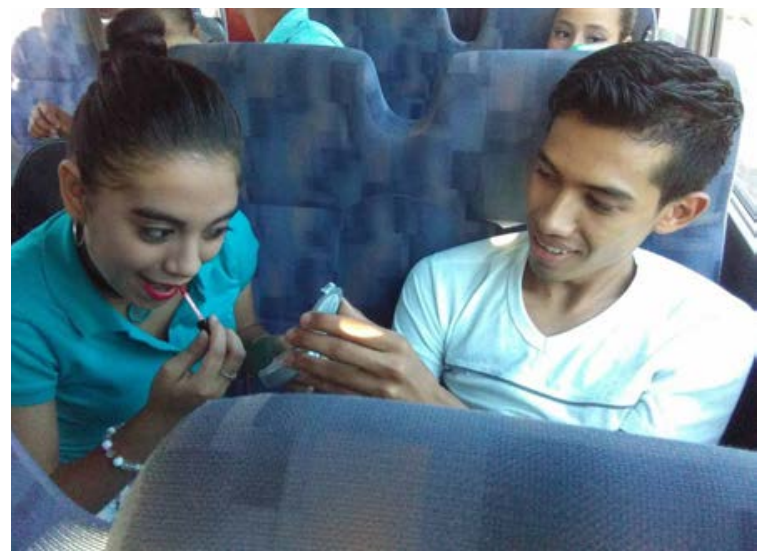

En viaje, preparándose para la presentación en la Comarca Cuajachillo. Abril 2016 (Foto: Lesbia Grijalva)

consistía en armar la coreografía con los pasos que la joven ya había montado.

En los ensayos no sólo la profesora organiza el trabajo, también los integrantes son copartícipes de la esquematización de cada número cultural, ya sea baile folklórico como variedades (bailes urbanos, ritmos latinos, otras danzas). A veces los jóvenes sienten temor de aportar porque la profesora a veces se molesta cuando no toman las prácticas con disciplina, pero abre el espacio para que contribuyan a realizar sugerencias y opiniones con los montajes. En otros casos deja a alumnos vanguardias que realicen y monten sus propias coreografías, pero interviene si hay algo que no le agrada.

El joven Junior Tobal, es uno de los jóvenes que muchas veces está apoyando en los ensayos, el comenta:

La profesora me ha dicho que les dé técnica, y varias partes que ya van mías ahí en alguna que otra coreografía. Trabajando los diseños y siempre creando porque cuando se crea una coreografía se crea con base, no se crea a la loquera, sino que se crea con una base de donde es qué y que significa este paso y que significa esa figura. (Tobal, 2014)

En presentaciones donde no todos pueden participan, se acomodan las coreografías a la cantidad de jóvenes disponibles y cuando son pocos, ellos mismos realizan coreografías que llaman "solos", es decir una pareja o un solo integrante puede ser mujer o varón, aunque generalmente es una joven.
La danza influye en la formación personal de cada uno de los estudiantes, ellos de diversas maneras implementan lo aprendido en los ensayos en la agrupación, ya sea en su comunidad de origen en lo que sean requeridos, grupos a los que anteriormente pertenecían y a nivel académico e intelectual, adquieren el compromiso de rescatar la cultura local y llevarla no solo al deleite del espectador sino también a la conciencia.

Todos coinciden en que han adquirido un conocimiento nuevo y que le es útil en su vida personal y también profesional. Puesto que han conocido de manera profesional y técnica la danza, se han abierto paso a nuevas experiencias, conocen nuevos lugares y nuevas expresiones artísticas danzarias, además de perder el miedo al estar en un escenario, lo que les ayuda a mejorar su expresión corporal, la seguridad al estar frente a un público y en sus carreras eso es importante por ejemplo a la hora que tiene que exponer, además que también no solo se quedan con conocimientos

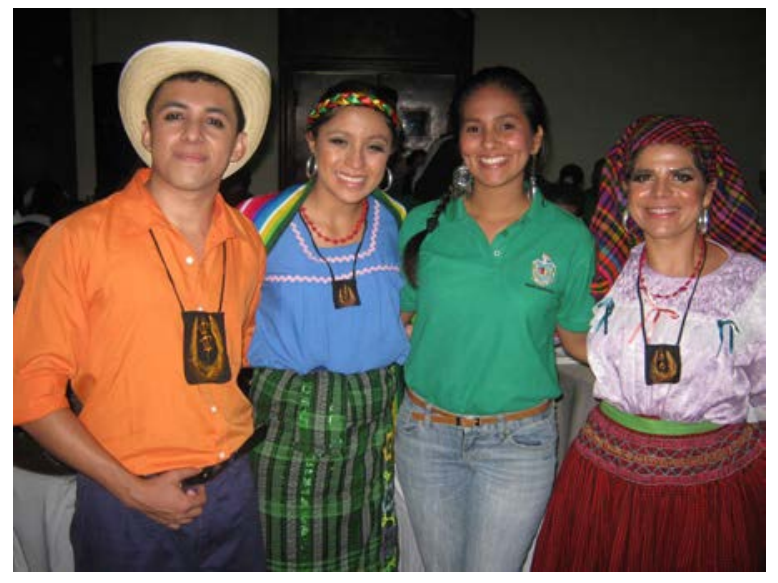

Pueblos Hermanos a través de la danza, FICCUA 2013, El Salvador, 2013 (Foto Edic Guzmán)

folklóricos, sino también otras danzas, las posturas y la cultura diversa que poseemos todos los nicaragüenses. Algunos comentaban que la importancia de lo aprendido también se ve reflejada en una nueva forma de subsistir, pueden impartir clases de danza, por lo que ya manejan además de lo básico, nuevos conocimiento y ven una oportunidad de crecimiento interno y adquisición de conocimiento. Aparte de la facilidad de socializar con las demás personas.

En lo personal me llena saber, de qué estoy aprendiendo algo muy nato de nuestro país y en lo profesional porque aparte de que podría ser una ayuda más adelante, los trabajos están muy difíciles, podría ser una ayuda todo el aporte que 
me ha dado la profesora en cuanto a danza se refiere y a pedagogía también. (García, 2014)

Como parte del relevo generacional, muchos también mencionan la oportunidad de compartir el conocimiento en su comunidad, Leez García comenta:

Hay muchos de los muchachos, integrantes del grupo que ellos ya tienen su propio grupo en su zona. Por ejemplo, Enrique Molina, fue uno de ellos, ahora ya no lo tiene porque casi ya no puede viajar, él tuvo su grupo allá, lo mantuvo por uno o dos años, dio un muy buen espectáculo, yo fui espectadora de eso y también Edwin tenía el suyo. Muchos de los muchachos tenían su grupo y creo que así es como van, se va expandiendo, se va distribuyendo el conocimiento que nos dio la profesora hasta hoy. (García, 2014)

\section{Mientras que Darling Oporta expresa:}

Tengo varios tíos y primos que participan en un grupo, entonces me piden ayuda tal vez alguna aportación para alguna coreografía o que les enseñe también alguna figura para que se vea bien en la coreografía y si, aporto bastantes ideas es decir el conocimiento que he adquirido aquí en la universidad. (Oporta, 2014)

Se podría decir que la información, técnicas, prácticas e incluso coreografías, se pueden ir adaptando a cada realidad de las comunidades de cada uno de los integrantes del grupo de danza Nicaragua Mía, dándole ese toque de originalidad, sin exclusión y con mayor profesionalismo.

La danza vista desde la perspectiva de aporte en la vida personal de los miembros del grupo, es de sentirse más nicaragüense porque están rescatando la cultura que los representa como nación, además de proyectarse académicamente con el deleite de practicar algo que les gusta, se ve reflejado en las palabras de Junior Tobal:

Considero que la danza es mi pasión. Aparte que estudio carreras técnicas y pienso estudiar alguna carrera que no sea danza, siempre pienso ser un bailarín profesional y crearme en el ámbito artístico y siento que no me afecta en nada, bailar por lo que ya manejo técnicas y esas cosas entonces uno se forma como bailarín profesional y cualquier coreografía se aprende y no hay complejos en ese sentido, porque el bailarín baila de todo. (Tobal, 2014).

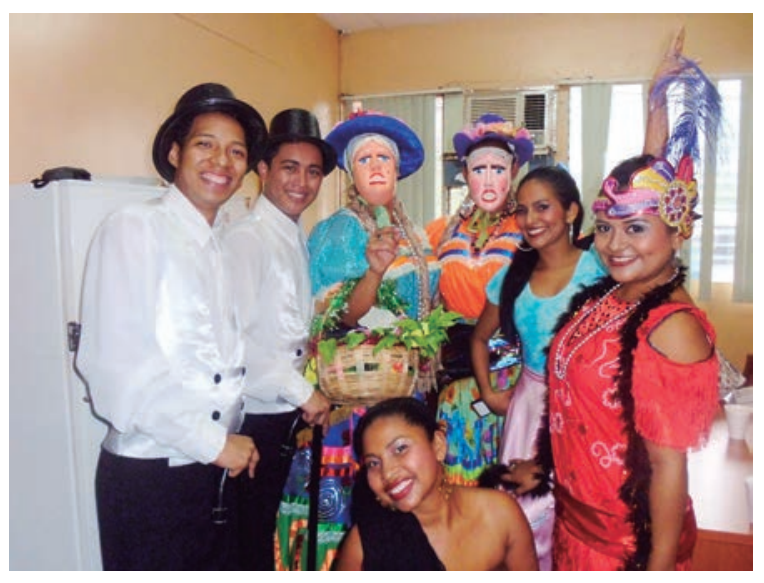

Compartiendo con los jubilados del INSS en el día del padre. Junio 2014 (Foto: Lesbia Grijalva)

\section{Aprendiendo del Otro}

Cuando somos espectadores generalmente es fácil criticar las presentaciones artísticas de danza de otros, sin embargo no nos damos cuenta de lo que pasa detrás del escenario, lo que pasó en el montaje de cada una de esas coreografías. Por eso darlo a conocer es importante.

Cada baile tiene su propia historia o bien un significado, esto se representa con un vestuario particular, accesorios, y lo más importante lo que se transmite con la expresión corporal. Para ello se trabaja desde el teatro, pequeños talleres para poder adoptar distintas personalidades, para transmitir la cultura e idiosincrasia de los nicaragüenses, protagonistas de su propia historia en esos bailes, pero eso si mantienen su estilo, pues se debe saber que cada grupo de danza tiene un estilo único.

Los integrantes de la agrupación son estudiantes de distintas carreras de la universidad, tienen diversas convicciones, cosmovisiones y cualidades, por lo que algunos son más aptos para un papel que otros; la instructora distribuye los lugares en la coreografía, los trajes; de acuerdo a tamaño, presentación y vestuario, por ejemplo en la representación de los ahuizotes de Masaya, califican a las y los jóvenes para ciertos papeles como el de las brujas que deben ser las más pequeñas y delgadas del grupo, pues los trajes son pequeños, mientras que las ceguas tienen que ser las más altas, al igual que los varones más altos y delgados que serían las quirinas o muertes. Primero trabajan en colectivo cada uno de los personajes, cuando ya son asignados los practican y estudian a mayor profundidad 


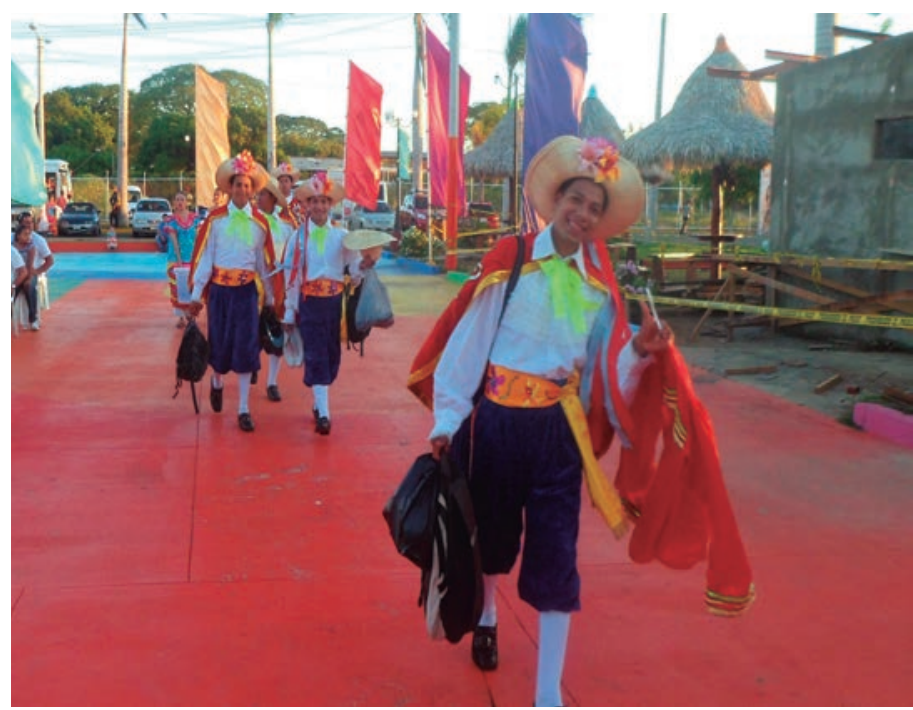

VIII Encuentro Regional de Danza Folklórica Plaza de los Colores, Puerto Salvador Allende. Octubre 2014 (Foto: Lesbia Grijalva) mente su música va al son de marimba; y es a la vez explícita cuando la historia está directa, en este caso ayudan tanto el vestuario, como la actuación de los participantes y la música principalmente, aquella que tiene letra, que narra la historia, además del ritmo y melodía.

La creatividad de cada estudiante, crece de manera técnica y metódica, aumentan su capacidad de pensar y evaluar lo que les parece bien y lo que no, aportan ideas y valoran las opiniones de los demás. Combinan ciertos elementos como dos músicas para formar una sola, en la que den a entender una misma temática, así también en el caso del vestuario, las herramientas que utilizan que facilitan las figuras, el tiempo programado para cada parte del baile y el orden de salida del escenario.
En fin, una serie de cosas que definen personalidades únicas que van adquiriendo dTe acuerdo a sus cualidades artísticas y físicas, sus gustos y proyecciones; adoptando nuevas costumbres, hábitos, cosmovisiones; desarrollando habilidades, destrezas y principalmente participando en la conservación de la cultura.

Cuando se comprometen a participar en alguna actividad, saben que deben ensayar, además que la profesora les exige, decir la verdad al no comprometerse si no van a participar, al igual que cuando le son entregados los trajes y accesorios del grupo, se les pide responsabilidad.

El dinamismo se ve tanto individual como en colectivo, comparten buenas ideas, los que ya conocen la técnica sin ningún miedo o vergüenza comparten los conocimientos con liderazgo, siempre con la supervisión de la profesora, ya que luego son divididos en grupos conforme a cada baile, luego cada uno de los grupos pasa a presentarlo frente a la maestra y así van corrigiendo y perfeccionándolos.

Los estudiantes progresan en adquisición de conocimientos, son capaces de emprender y auto motivarse, de captar y expresar el baile por medio de la expresión corporal, la historia que está detrás que puede ser implícita; cuando el baile es representativo de acuerdo a la coreografía, vestuario y actuación del mismo por parte de sus integrantes, un tanto oculta por así decirlo y buscando que sea descubierta y entendida y general-
Se toman el tiempo necesario para digerir las cosas, tratan de comprender y aprender, piden ayuda a los alumnos más destacados, se puede ver el interés y perseverancia. Cuando ya han aprendido los pasos y coreografía, se trabaja el estilo propio de cada baile; dorso, brazos, postura, en algunos casos cabeceo, forma de interacción con su pareja y con el colectivo, las direcciones, la sonrisa, la manera de utilizar los instrumentos (en los hombres el sombrero y a veces los machetes y en las mujeres la falda, el rebozo, canastos, abanicos, guacales y pañuelos). Le dan a cada baile una parte original de cada uno de ellos y ésto se ve reflejado en la presentación, como marcan cada paso, la flui-

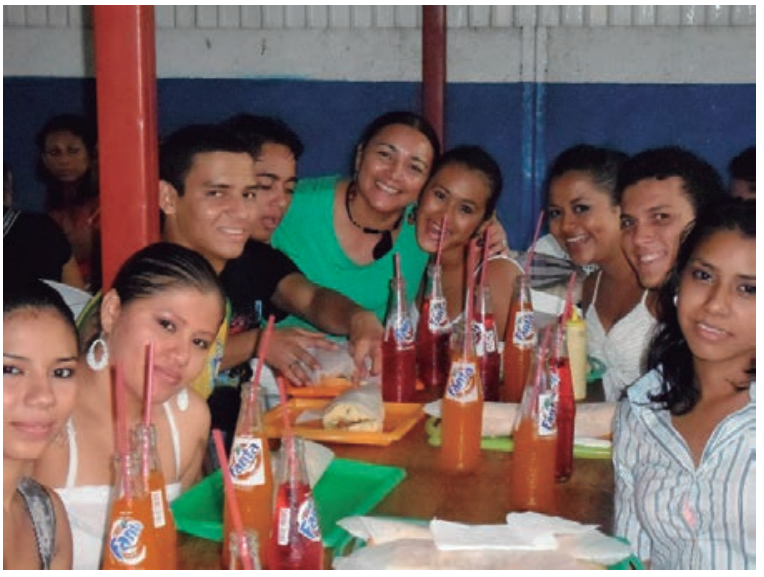

Socialización en el Cafetín, Zona 1 UNAN- Managua. Julio 2011 (Foto: Lesbia Grijalva) 
dez de su baile e incluso su propia sonrisa y expresión en el rostro que les da seguridad.

Por otro lado están abiertos a hacer otras actividades como ordenar el vestuario conforme baile, sexo y categorías. Igualmente pasa con los accesorios, como: sombreros, máscaras, zapatos, trenzas, abanicos, pañuelos, etc. También reparan algunos accesorios o los crean como las trenzas y sombreros, cuando se dañan solo compran el material y trabajan en conjunto con la profesora quien dirige el trabajo. Aparte que da las debidas recomendaciones acerca del cuido del mismo.

Se realizan otras actividades como las despedidas de semestre, donde se organizan y piden patrocinio para luego reunirse y compartir todos por igual. Cuando es fin de año, despiden a compañeros que están saliendo de sus carreras, se premian a alumnos por votación de todos, se hacen juegos, entre otras cosas. Y como amigos comparten momentos reunidos en determinadas casas principalmente las asignadas para becadas culturales.

La amistad juega un papel importante, pues mediante a esa afinidad aprenden costumbres, tradiciones del otro, pues intercambian experiencias propias vividas en sus contextos de procedencia, conocen mediante esa convivencia, la cultura de los lugares del país.

\section{Discusión de resultados}

El Grupo de Danza Nicaragua Mía es un marco para la convivencia, pues en ello convergen jóvenes de diversas culturas: el grupo en sí es multicultural, pero

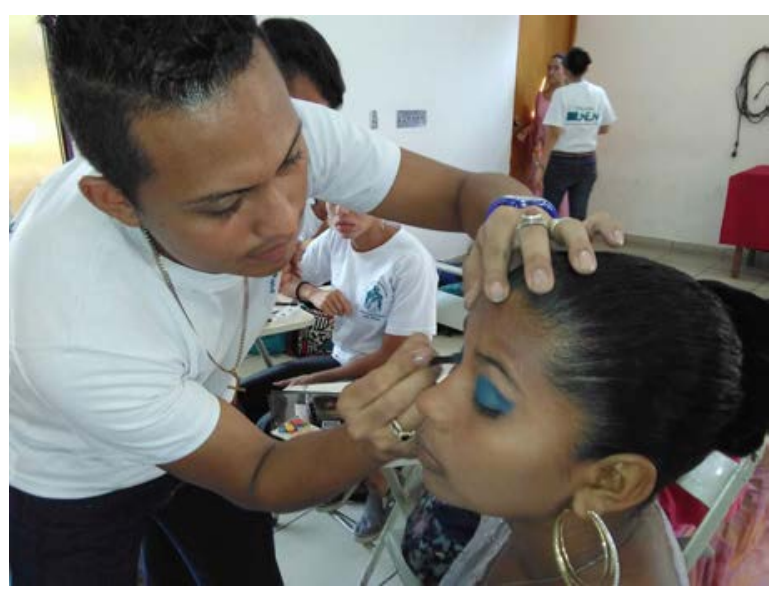

Preparación para el X Encuentro Regional

Danza Folklórica. FAREM Matagalpa. Junio 2016

(Foto: Lesbia Grijalva) la transformación hacia la interculturalidad está dada por las relaciones interpersonales entre sus miembros. Es un espacio en el que los protagonistas se ven identificados por el respeto a su cultura, creencias, identidad y la desarrollan en la danza.

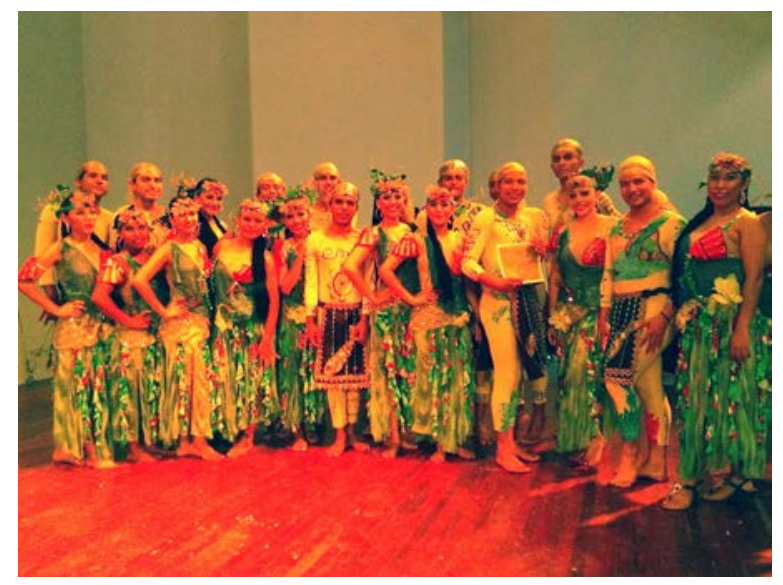

Cultura y Tradición Étnica. Matagalpa junio 2016 (Foto: Lesbia Grijalva)

El surgimiento de este grupo no es del conocimiento de los integrantes actuales de este grupo, pero es porque el grupo está en constantes cambios, por lo que sus integrantes solo estudian por cinco años en la carrera y aunque dilataran más tiempo en ellas. Éstos pertenecen al grupo por ser becados internos y el tener una beca exige tener un buen promedio, por lo que si reprueban clases, no tendrían una beca interna y por ende no serían parte del grupo, ya que los ensayos son por la noche. Aunque no es prohibida la entrada de alumnos externos, es decir que no sean becados internos, el grupo es bastante accesible, en ese sentido, pero esos alumnos externos tendrían que viajar y no todos pueden estar viajando de noche.

Para los integrantes del grupo no es indispensable conocer cómo surgió el grupo y muchos de ellos puedo decir que la mayoría, no conocía de la existencia del grupo, previo a venir a la universidad. Es más los motivos por los que decidieron entrar varían, pues unos entraron por el gusto a la danza, otros sin embargo entraron por lograr tener una beca cultural, sea la monetaria o el alojamiento en el internado, pues debido a su promedio de notas obtenidas en el semestre, no lograron el porcentaje requerido para optar por la beca y bien otros entraron para aprender a bailar, como pasatiempo, ejercicio y relajación, ya que esta actividad de alguna u otra manera despeja la mente el trabajar el cuerpo. 
En las clases podemos darnos cuenta que la instructora utiliza algunas estrategias de enseñanza-aprendizaje, para lograr que cada estudiante aprenda asimilando cada baile a la cotidianeidad de las realidades e historias de su país.

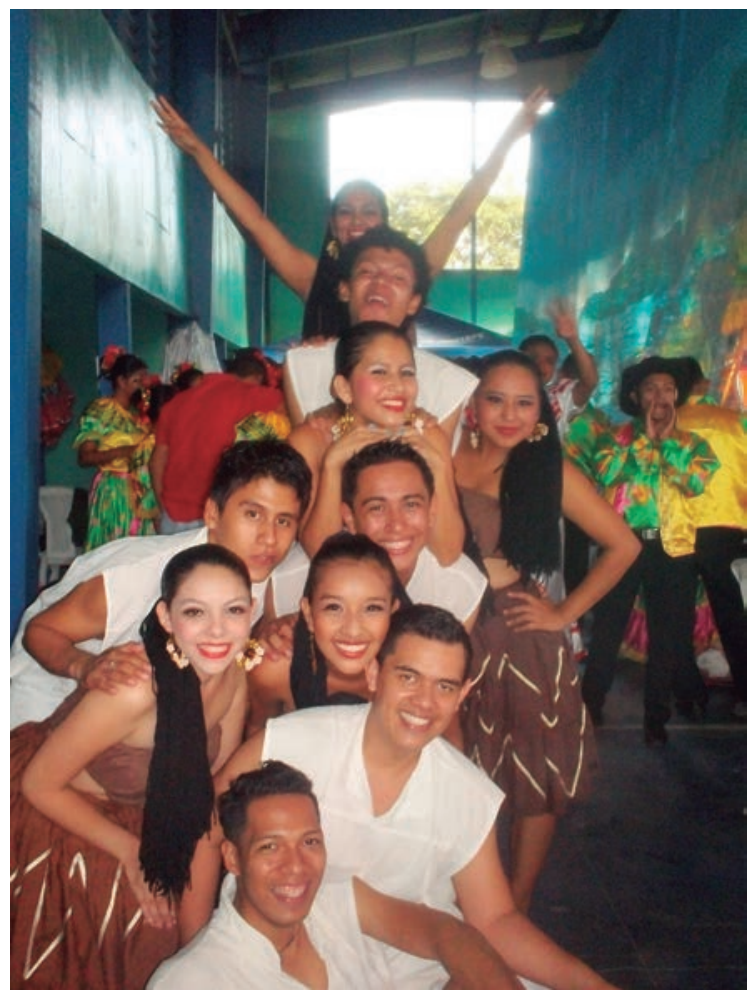

VII Encuentro Regional de Danza Folklórica,

Carazo. Septiembre 2013

(Foto: Lesbia Grijalva)

La manera de hacer el trabajo compartido, de reproducir el conocimiento y de desarrollar lo aprendido dentro del grupo, es como los integrantes se vuelven mediadores culturales, pues retoman los aportes de cada uno de ellos y esos caben en cada coreografía a presentar, el grupo se vuelve participativo, la maestra actúa como mediadora intercultural pues regula, guía y es la que acomoda cada número con esos aportes.

Muchas veces son los estudiantes que saben cómo son los bailes tradicionales de su comunidad, pues ellos la viven, entonces la profesora con el fin de conservar la cultura, permite que sean los jóvenes quienes enseñen como se hace, el trabajo de ella radica en las coreografías, en donde se acomodan los pasos, cuanto tiempo y las figuras que armarán.
Así la participación de los jóvenes recrea una visión de cada lugar del país más completa pues es escuchada de un poblador y originario de determinado pueblo del país. Aprenden unos de otros a medida que realizan una práctica cultural como lo es la danza folklórica nacional, además de conocer e interpretar otros ritmos latinos y extranjeros. También, impulsar capacidades personales necesarias en un escenario, tales como: pérdida del miedo escénico, oratoria, expresiones corporales, entre otras, y así mejorar la seguridad.

Todos tienen afinidad, unos más con unos que con los otros, pero se dan esos lazos de amistad, no sólo son compañeros sino amigos, se ayudan entre si y esto facilita el trabajo, ya que en los ensayos los que aprenden más rápido, o bien conocen la técnica, sirven de apoyo a la profesora para acelerar el proceso de aprendizaje, otros están a la expectativa de cualquier error o alguna actividad que no les parezca o no les guste y así aportan mejoras para la coreografía.

Se puede lograr un trabajo de calidad aprovechando las cualidades de los estudiantes, las inferencias de cada uno, el compañerismo, la creatividad y el ser mediadores culturales hace que cada baile este lleno de la verdadera cultura, la manera de como la diversidad incide y ver que la danza y la interculturalidad puedan estar de la mano.

\section{Conclusiones}

Se concluye que el grupo de danza Nicaragua Mía de la Unan-Managua, tiene de funcionar trece años, los miembros están en constante cambio, debido a que concluyen con sus carreras universitarias y posteriormente toman rumbos diferentes, es por esta razón que los jóvenes que pertenecen actualmente, a pesar de tener un largo tiempo en el grupo, no manejan el año exacto de su fundación.

Al cambiar de contexto, se pueden observar diferentes culturas, formas de ver el mundo y diferentes expectativas de futuro. Un grupo de danza es visto como una forma de interactuar, para otros de pasatiempo, una forma de relevo generacional, o bien para conseguir una beca cultural.

Factores como: las creencias religiosas, las prácticas populares, tradiciones, el habla, la familia, comunidades indígenas, las regiones de procedencia, entre otros aspectos que constituyen una cultura particular, inciden al momento en que los integrantes llegan a esta agrupación de danza ya que se constituye una diver- 
sa multiculturalidad y este espacio se convierte en un marco para la convivencia intercultural, que no afecta en el desarrollo como grupo, pues se convierten en mediadores, siempre guiados por la maestra, la principal mediadora intercultural, pero estos conocimientos influyen en el logro de la sinergia de la interculturalidad y la danza misma como su resultado.

\section{Recomendaciones}

A la Universidad:

Sirva el presente estudio como referencia a estudiantes de la carrera de danza, para apoyo didáctico.

Por lo que se sugiere a las autoridades de la UNAN-MANAGUA, la divulgación del presente dentro de la licenciatura de danza, carreras afines y directores de agrupaciones danzarias.

\section{Al Grupo de Danza:}

Incorporar talleres de corta duración con base en el material de este trabajo, porque no se conoce a profundidad el origen histórico del grupo de danza.

\section{Agradecimientos}

A Dios, por ser mi guía en cada momento, quien por sobre todo ha hecho posible la publicación de este artículo.

A mi familia y amigos que me ayudaron en logística con las herramientas a utilizar y la motivación en la perseverancia para lograrlo.

Agradezco a las personas que me permitieron entrar a su espacio, hacer entrevistas, brindarme su tiempo:

$>$ MsC. Lesbia Grijalva Matamoros, Instructora del Grupo de Danza Nicaragua Mía.

> Integrantes del Grupo de Danza Nicaragua Mía 2014-2015.

Lic. Álvaro Zambrana, Director del Departamento de Becas 2014.

A mi tutora de investigación, Lic. Jossarys Gazo, por darme acompañamiento, revisión general, correcciones.
A la Dra. Cecilia María Costa, por instruir y compartir sus conocimientos acerca de la publicación del artículo científico.

\section{Bibliografía}

Aguirre, A. (1995). Etnografía: Metodologia Cualita tiva en la Investigación Sociocultural. Barcelona: Boixareu Universitaria Marcombo.

Atkinson, P. (1994). Etnografía Métodos de Investigación . Madrid: Paidós Ibérica.

Castilllo, Lengua, L. (2011). Caracterización psicométrica de un instrumento de clima organizacional en el sector educativo universitario Colombiano. International Journal or Psychological Research, 4(1), 40-47.

Delgado, A. A. (Junio de 2002). Gazeta de Antropología. Obtenido de http://www.ugr.es/ pwlac/ G18_14Angel_Acuna_Delgado.html

Grijalva Matamoro, L. d. (2013). El comportamiento social y la diversidad cultural en el Grupo de Danza Nicaragua Mía de los becados internos en la UNAN-Managua. Managua: UnanManagua.

Guber, R. (2001). La etnografía, método, campo y reflexividad. Bogotà: Norma.

Joshert, A. (20 de Octubre de 2008). Teatro: Cultura Artística en ICESI. Recuperado el Noviembre de 2013, de http://ej-cali.blogspot.com/

León Báez, J. (2011). La Máscara y su prescencia en Nicaragua. Managua: Fondo editorial INC.

Naranjo, L. M., \& Gonzalez, F. M. (2001). Inserción de los proyectos pedagógicos de aula en las prácticas profesionales de la docencia. MULTICIENCIAS- Ciencias de la educación, 1(2), 117-128. 
Pastor, B. G. (23 de Noviembre de 2007). Introducción a la Mediación Intercultural en el ambito educativo. Recuperado el 24 de Agosto de 2015, de Introducción a la Mediación Intercultural en el ámbito educativo.: http:// www.tonosdigital.es/ojs/index.php/tonos/article/viewFile/182/142

Taylor, E. (1871). La cultura Primitiva. Gran Bretaña.

\section{Entrevistas realizadas}

Centeno, R. (05 de Junio de 2014). Patrones culturales que inciden en el comportamiento. (D. Paizano, Entrevistador)

García, L. (05 de Junio de 2014). Patrones culturales que inciden en el comportamiento. (D. Paizano, Entrevistador)

Oporta, D. (05 de Junio de 2014). Patrones culturales que inciden en el comportramiento de los integrantes del grupo de danza. (D. Paizano, Entrevistador)

Reyes, D. (05 de Julio de 2014). Patrones culturales que inciden en el comportamiento. (D. Paizano, Entrevistador)

Tobal, J. (05 de Junio de 2014). Patrones culturales que inciden en elos comportamientos. (D. Paizano, Entrevistador) 